\title{
SEBUAH RUPA “JAWA” DALAM KALANGWANG
}

\author{
Arif Kurniar Rakhman \\ Peneliti Sastra dan Budaya di Komunitas Kembang Merak \\ Email: jek_arifrakhman@yahoo.com
}
Judul Buku: Kalangwan: Sastra Jawa Kuno Selayang Pandang |
Pengarang: P.J. Zoetmulder | Penerbit: Penerbit Djambatan |
Jumlah Halaman: 648 HaLAman

\section{Sang byang candra bangun bahitra dateng ing kulem anawa sasa mareng Jawa.}

(Sumanasataka 33.4 via Zoetmulder, 1985 :238)

B agaimana menyimak identitas Jawa dalam "rupa-rupa" riwayatnya? Sebuah pertanyaan ringan sengaja terlontar ketika pikiran kita mengimajinasikan "Jawa" dalam sebuah multi ruang, mengingat cairnya narasi yang diriwayatkan dari berbagai pilihan sudut pandang. "Jawa" bisa kita hadirkan dalam sebuah perspektif geografis, yaitu dari Anyer hingga Panarukan. Artinya, memahami "Jawa" di luar itu adalah "bukan Jawa", meskipun Sunda-yang secara wilayah masuk "Jawa"-, tidak akan pernah merasa dirinya sebagai "Jawa" akibat proses kontestasi antara kerajaan Padjajaran dan kerajaan Majapahit yang terus direproduksi. Kemudian, memahami "Jawa" dari perspektif keraton tentu menghadirkan "Jawa" dalam nuansa yang feodalistik, jauh dari gagasan-gagasan yang terkesan modern dan rasional. Hal ini tentu memberikan konsukuensi bahwa citra "Jawa" adalah masa lalu, berbentuk klangenan, dan tidak relevan dengan era sekarang. Padahal di konteks lain, harmonisasi alam yang selalu dikampanyekan hari ini, sudah sejak lama dihadirkan melalui berbagai teks dan tradisi "Jawa", melalui modal simbolik yang dihadirkannya. Nyi Loro Kidul mungkin menjadi pilihan kampanye yang signifikan pada masanya untuk menjaga laut agar tetap asri dan terbebas dari eksploitasi manusia. Memahami
"Jawa" bisa juga menafsirkannya dalam gagasangagasan yang lebih politis, yaitu lemah lembut di depan, kemudian menghujat di belakang. Cara pikir ini tentu menghadirkan "Jawa" sebagai pengecut, bukan "Jawa" yang gagah. Padahal di konteks lain, sejarah kerajaan di Jawa selalu berkontestasi, bahkan selalu menghadirkan resistensi antartokoh yang berkuasa. Tentu untuk merebut pengaruh dan hegemoni kekuasaan secara gagah, perang Diponegoro bisa menjadi referensi yang menarik.

Itulah kenapa "Jawa" menjadi sangat seksi untuk dikaji, terutama oleh para sarjana Barat, simak Clifford Geertz, Bennedict Anderson, Deniel S. Lev, Nancy K.Florida, Andre Moller, atau bahkan P.J. Zoetmulder yang memosisikan "Jawa" sebagai objek kajian. Dari kajian-kajian itu ternyata "Jawa" juga tidak dipersepsikan sama.P.J. Vent(1875) memberikan komentar bahwa orang Jawa selain mahir dalam pertanian dan perdagangan, juga mahir dalam meracik tembaga, memahat, bahkan mengecor logam. Konteks ini berbeda dengan Mulder (1980) yang menganggap orang Jawa tidak terlalu punya perhatian yang intens terhadap benda mateial dan kecakapan material. Dunia kemudian dianggap remeh dibandingkan sisi spiritual yang hadir. Komunikasi praktis tidak dihargai, sedangkan komunikasi sosial memiliki derajat lebih penting. Memang benar, dimensi waktu dan tempat bisa menjadi indikator mengapa penelitian keduanya berbeda. Namun, tetaplah ada pesan bahwa "Jawa" selalu dinamis. Artinya, semua narasi atasnya pasti hadir dalam 
"rupa-rupa" yang berbeda. Maka, istilah "ruparupa" adalah pilihan kata untuk membedakan dengan kata "sebuah rupa", agar tidak terkesan tunggal.

Berdasarkan kesadaran itu, cara pikir kita hendaklah memilah "Jawa" dalam ruparupa yang berbeda. Rupa yang satu tentu berbeda dengan rupa yang lain karena rupa yang lain menjadi tanda bagi hadirnya rupa yang satu. Termasuk ketika kita memahami "Jawa" dalam wujud teks sastra kunonya, tentu dia menjadi tanda akan hadirnya rupa yang baru, sebuah rupa lain yang entah sudah atau justru belum terkaji. Inilah pentingnya dunia rupa "Jawa" yang saling menyambut. Untuk itu, tetap diperlukan sebuah kajian yang komprehensif agar membuka ruang yang satu, terutama terkait dengan sastra Jawa kuno dan berbagai hal yang melingkupinya, agar terbuka rupa-rupa yang lain. Zoelmulder lewat buku Kalawang: Sastra Jawa Kuno Selayang Pandang mencoba menawarkan itu.

Ada banyak hal yang patut diapresiasi dalam buku ini. Kekayaan dalam deskripsi data karya sastra Jawa kuno, dari yang mayor hingga minor, adalah hal yang paling istimewa ketika kita membaca buku ini. Simak bagaimana buku mendeskripsikan sastra purwa, misalnya Adiparwa (hlm 80-84), Wirataparwa (hlm 84-86), Udyopagarwa (hlm 86-89) dan lain sebagainya, berbagai jenis kakawin mayor seperti ikhtisar Ramayana (hlm 278-288), ikhtisar Arjunawiwaha gubahan Mpu Kanwa (hlm 298-308), hingga beberapa kakawin minor dari Subhadrawiwaha sampai Naraka Wijaya (hlm 480-507). Tidak lupa, eksplorasi Sastra Kidung hadir dalam buku ini, seperti Ikhtisar Kidung Harsawijaya hingga Ikhtisar Waseng Sari (hlm 513-539).

Kelebihan lain yang tercermin dari buku ini adalah kemampuannya meraba aspek sosiologis dan historis teks. Sebuah kutipan Sumanasataka 33.4 di atas adalah salah satu contoh yang menarik. Sarjana dari Belanda ini menjelaskan bahwa makna teks pasti bukanlah bulan baru karena kutipan tersebut merupakan deskripsi laut menjelang fajar; hanya pada saat itulah bulan purnama dapat dikatakan telah datang pada malam hari. Selain itu, hanya bulan purnamalah yang mencerminkan ciri-ciri seekor Kelinci (hlm 238). Di konteks lain, posisi Jawa dalam teks itu hanyalah suatu anakronisme, atau sekurang-kurangnya sebagai suatu anatopisme, mengingat latar cerita, nama kerajaan, bahkan nama tokoh sebenarnya berasal dari India. Model seperti teks ini juga hadir dalam kakawin lain, seperti tokoh Arjuna bertangan seribu (Arjuna Sahasrabahu), kisah mengenai Rama dengan kapaknya (Parasurama) atau dari lingkungan mitologi, dengan munculnya dewa Siwa, Wisnu, dan raksasa. Artinya, latar belakang cerita tersebut hadir dari observasi penyair sendiri tentang dunianya, yaitu perpaduan dunia nyata dan dunia imajinasinya (hlm 239).

Selain itu, penjelasan tentang harmonisasi alam dengan manusia menjadi pilihan analisis yang menarik dari tulisan Zoetmulder ini. Hal ini menjelaskan bagaimana metafora-metafora menjadi sarana-sarana sastra dan menjadi sumber bagi sejarah kebudayaan Jawa kuno. Ada beberapa contoh yang bisa dideskripsikan, misalnya deskripsi tentang kecantikan perempuan dikatakan bahwa rambutnya hitam dan tebal laksana awan-awan yang jenuh dengan hujan lebat, raut mukanya laksana rembulan, bibirnya merah laksana katirah, lengannya lentur dan ramping laksana ranting-ranting pohon asoka, payudaranya laksana buah kelapa gading, serta betis yang berbentuk indah menyerupai pudak (hlm 267). Hal yang berbeda ketika mendeskripsikan prajurit-prajurit yang merepresentasikan sifat perkasa. Dijelaskan ketika Bhima membunuh Dussasana, rambutnya menyerupai awan yang kemerah-merahan, matanya bersinar bagaikan matahari yang terbakar, sendawanya terdengar bagaikan gemuruh guntur (genter), dan tubuhnya bertetesan darah seperti awan yang diwarnai matahari (hlm 268). Dari deskripsi ini, ada unsur pokok dalam alam pikiran Jawa kuno, yaitu manunggaling (bersatunya) alam semesta dengan makhluk yang ada di dalamnya (hlm 269).

Zoetmulder juga menjelaskan tentang 
produksi dan teknik penulisan teks dalam buku ini, karena baginya proses penulisan teks adalah proses kebudayaan yang harus dicermati. Kita harus membayangkan proses penulisan yang terjadi pada saat itu dalam keterbatasan. Padahal keterbatasan itu adalah persoalan utama dalam menyusun sebuah teks (puisi) dalam masyarakat Jawa kuno (hlm 150). Dalam penjelajahan yang dilakukan Zotmulder, daun-daun palma/ental atau lontar (suatu bentuk metatesis dari rol tal, yaitu au pohon tal) adalah bahan tulis tersebut (hlm 152). Selain itu, ada juga pudak, yaitu bunga pohon pandan, suatu jenis tanaman yang mirip dengan nanas. Tanaman ini sering tumbuh di sepanjang pantai dan sungai. Bunganya ( $p$ udak) tersusun menurut lapisan, berwarna kuning, terbungkus lonjong yang pada ujungnya meruncing. Menurut Zoetmulder, bunga ini sering diumpamakan dengan betis seorang peempuan, bila kainnya terbuka sedikit (hlm 161). Ada juga alat tulis lain seperti tanah dan karas, meskipun proses pemaknaan terhadapnya masih memerlukan penafsiran lebih lanjut karena informasi ini datangnya justru dari teks sastra Jawa kuno sendiri (hlm 154-155).

Keunggulan lain dari buku ini adalah penjelasan Zoetmulder tentang deskripsi relasi Kawi (penyair) dengan raja yang dijunjungnya. Simak bagaimana Zoetmulder memberikan penjelasan tentang $m p u$ Kanwa yang menggubah syair Arjunawiwaha. Disebutkan bila istilah samarakarya/operasi militer/perang kita terima menurut arti yang sebenarnya, maka rupanya syair ini ditulis pada tahun 1028 dan 1035. Sangat masuk akal bahwa manggala-nya ditujukan kepada Erlangga, biarpun namanya tidak disebutkan. Artinya, sangat jelas bahwa penyair yang bernama mpu Kanwa menulis syairnya di bawah perlindungan raja Erlangga (hlm 308-309). Relasi ini juga tercermin antara kawi yang lain dengan raja-rajanya, seperti mpu Tantular dengan Hayam Wuruk (hlm 429), Prapanca dengan Hayam Wuruk (440-450), mpu Monaguna dengan Warsajaya, seorang raja setelah Erlangga (hlm 385) dan lain sebagainya. Meski banyak sekali keunggulan dari buku ini, ada beberapa kritik yang mestinya harus dilontarkan sebagai wujud keseimbangan informasi. Zoetmulder dirasa masih belum mampu menjembatani teks sastra mayor sebagai wujud dari sastra istana, melalui pemujaan kepada raja, dengan sastra yang minor yang merupakan sastra yang tidak berbicara pada istana sentris, meskipun data terhadap sastra ini sulit sekali dilacak. Mungkin penelusuran terhadap sastra lisan, sebagai representasi dari sastra minor dan media oposisi dari sastra mayor, bisa menjadi pintu yang menarik untuk diteliti. Proses observasi yang dilakukan Zoetmulder di Bali mestinya juga bisa melacak itu, sehingga data yang didapat tidak hanya terpaku pada proses mekanisme penulisan sastra Jawa kuno saja. Sayangnya, hal ini tidak dilakukan. Meskipun begitu, usaha itu terlihat ada dengan minimal melakukan eksplorasi berhadap beberapa kakawin yang tidak begitu populer (dalam konteks yang lain bisa menjadi sastra minor), meskipun tetap berada pada lingkup istana sentris. Hal lain yang juga kurang dilakukan adalah usaha untuk mencari geneologi teks sastra kuno karena tentu banyak sekali versi naskah yang diteliti. Dengan melakukan langkah itu, minimal pembaca bisa mengetahui naskah versi mana yang diteliti, sehingga langkah-langkah penelitiannya, seperti metode dan teori, juga bisa menjadi perbincangan yang hangat di kalangan penikmat sastra.

Akhirnya, kehadiran buku Kalawan: Sastra Jawa Kuno dan Selayang Pandang karya P.J. Zoetmulder patut diapresiasi karena telah memberikan informasi yang sangat detail tentang teks Jawa kuno, mulai dari ikhtisarnya hingga hubungan kekuasaan yang melingkupinya. Selain itu juga menjadi pintu masuk untuk membuka rupa-rupa identitas "Jawa" yang lain, sebuah rupa yang tidak mesti harus berbaur dengan istana dan kekuasaan, sebuah rupa yang menjelaskan bahwa "Jawa" tidak dalam narasi tunggal. Semoga. [] 